\title{
PENGGUNAAN BRAND AWARENESS SEBAGAI MEDIASI ANTARA ADVERTISING DAN PURCHASE DECISION PRODUK FASHION ONLINE
}

\author{
Krismi Budi Sienatra \\ Fakultas Manajemen dan Bisnis Universitas Ciputra \\ krismi.budi@ciputra.ac.id \\ Aliefiah Pranedya \\ Fakultas Manajemen dan Bisnis Universitas Ciputra \\ aliefiahpranedya@ymail.com
}

Masuk : 24-08-2020, revisi : 26-08-2020 diterima untuk diterbitkan : 02-09-2020

\begin{abstract}
The important thing that needs to do and considered by every company is creating new customers and retaining old customers by always being active in product promotion, one of them is advertising. Most companies rely on and use advertising in order to increase the opportunity for more widely known products so that they can create a brand awareness. The purpose of this study was to mock the advertising influence on the purchasing decisions of online fashion products with brand awareness as a mediating variable. This study contained independent variables (Advertising), dependent variables (Purchase Decisions) and mediating variables (Brand Awareness). The study was conducted by taking a sample of 52 people who had already bought fashion online products with ASTYLE brand. The analysis technique use in this study is Path Analysis. The results showed that advertising had a significant effect on brand awareness of products, advertising had a significant effect on the purchasing decisions of ASTYLE products and brand awareness had a significant effect on purchasing decisions for online products.
\end{abstract}

Keywords : Advertising, Brand Awareness, Purchasing Decisions

\begin{abstract}
Abstrak : Hal penting yang perlu dilakukan dan diperhatikan oleh setiap perusahaan adalah menciptakan pelanggan baru dan mempertahankan pelanggan lama dengan cara selalu aktif dalam melakukan promosi produk salah satunya dengan advertising guna memperbesar peluang agar produk lebih dikenal secara luas sehingga dapat menciptakan sebuah brand awareness. Tujuan dilakukannya penelitian ini adalah untuk mengeji pengaruh advertising terhadap keputusan pembelian produk fesyen online dengan merek ASTYLE dengan brand awareness sebagai variabel mediasi. Penelitian ini terdapat variabel bebas (Advertising), variabel terikat (Keputusan Pembelian) dan variabel mediasi (Brand Awareness). Penelitian dilakukan dengan mengambil sampel 52 orang yang sudah pernah membeli produk fesyen online merek ASTYLE. Teknik analisis yang digunakan dalam penelitian ini adalah analisis jalur (Path Analysis). Hasil penelitian menunjukkan bahwa advertising berpengaruh signifikan terhadap brand awareness produk, advertising berpengaruh signifikan terhadap keputusan pembelian produk dan brand awareness berpengaruh signifikan terhadap keputusan pembelian produk.
\end{abstract}

Kata Kunci : Advertising, Brand Awareness, Keputusan Pembelian

\section{PENDAHULUAN}

Perkembangan bisnis fesyen pada era globalisasi saat ini mengalami peningkatan sangat pesat. Hal ini dapat dilihat bahwa persaingan dunia usaha fesyen semakin ketat. Beberapa tahun ini sektor Ekonomi Kreatif menyumbang 7,38\% terhadap total perekonomian nasional tahun 2016, dimana sektor fesyen berkontribusi sebanyak 18,15\%, (Badan Ekonomi Kreatif 2017). Perkembangan dunia fesyen saat ini menyebabkan banyak bisnis yang bergerak dibidang 
fesyen seperti brand ASTYLE sejak 2016 yang memproduksi scarf yang mengikuti tren masa kini dan dipadukan desain budaya Indonesia. ASTYLE aktif dalam melakukan promosi salah satunya dengan advertising guna meningkatkan penjualan serta produk yang dipasarkan semakin dikenal dikalangan masyarakat luas (Oladepo \& Abimola, 2015). Dalam melakukan kegiatan promosi khususnya advertising, ASTYLE memanfaatkan media sosial Instagram yang menyediakan fitur untuk mengiklankan produk. ASTYLE juga melakukan endorse pada selebriti yang pernah ASTYLE gunakan jasanya yang berfokus pada lifestyle dan gaya berbusana. Endorse digunakan untuk karena endorser banyak dikenal masyarakat dan terlibat langsung dalam promosi sebagai pendukung langsung atau tidak langsung (Yunus, 2015)

Hal penting yang perlu dilakukan dan diperhatikan oleh setiap perusahaan adalah menciptakan pelanggan baru dan mempertahankan pelanggan lama dengan cara selalu aktif dalam melakukan promosi produk salah satunya dengan advertising (Putra \& Rachmi, 2017). Sebagian besar perusahaan mengandalkan dan menggunakan advertising guna memperbesar peluang agar produk lebih dikenal secara luas sehingga dapat menciptakan sebuah brand awareness. Brand awareness juga menjadi bahan pertimbangan bagi para konsumen dalam menentukan pilihannya, karena kebanyakan orang akan membeli produk yang mereka kenal sebab konsumen telah memberikan kepercayaannya terhadap kualitas dan manfaat yang diberikan produk tersebut (Timpal et al., 2016). Kegiatan promosi lain diikuti dengan cara direct marketing yaitu mengikuti pameran skala Internasional dan ditunjang dengan kegiatan promosi melalui advertising yang juga menjadi faktor pendukung konsumen datang ke pameran. Keputusan konsumen kemungkinan besar timbul dari pengalaman pembelian sebelumnya yang didukung oleh advertising yang menarik dan brand awareness yang kuat sehingga keputusan pembelian konsumen menjadi penting dalam faktor eksistensi suatu perusahaan dalam memutuskan pembelian produk dari suatu pasar yang memicu respons positif rangsangan konsumen dari pasar itu sendiri. Melihat sebuah fenomena bahwa kesadaran konsumen masih rendah pada produk ASTYLE, maka penelitian mengenai peran brand awareness memediasi pengaruh advertising terhadap keputusan pembelian produk ASTYLE menjadi ketertarikan peneliti untuk melakukan penelitian lebih lanjut.

\section{TELAAH KEPUSTAKAAN Advertising}

Menurut Ariprayugo dan Santoso (2016: 4) periklanan adalah bentuk komunikasi tidak langsung dengan dasar informasi mengenai keunggulan atau keuntungan suatu produk, yang disusun sehingga timbul rasa senang yang akan mengubah pikiran seseorang untuk melakukan pembelian. Siregar dan Widodo (2018: 1134) konsumen berpendapat bahwa iklan sebagai jendela informasi sebagai arahan dalam memilih produk. Di lingkungan perusahaan iklan merupakan media promosi yang efektif untuk mengenalkan produk pada masyarakat. Sebagai calon pembeli tentunya konsumen perlu mengetahui informasi yang jelas tentang produk yang di iklankan. Melalui informasi yang ada dan jelas pastinya konsumen akan memiliki keputusan untuk membeli. Terdapat indikator menurut Ariprayugo dan Santoso (2016: 4) yang sesuai dan diambil oleh peneliti untuk digunakan pada penelitian ini yaitu,

1. Penemuan informasi tentang produk mudah.

2. Informasi yang disampaikan di media sosial Instagram jelas.

3. Pesan yang terkandung dalam media sosial Instagram dapat dipercaya.

\section{Brand Awareness}

Menurut Iskandar dan Sari (2017: 284) brand awareness adalah kemampuan seorang calon pembeli untuk mengenali dan mengingat kembali suatu merek sebagai bagian dari suatu kategori produk tertentu. Bangun dan Saputri (2016: 2078) advertising memiliki pengaruh terbesar terhadap brand awareness, meskipun publisitas penjualan personal dan promosi penjualan juga bisa meningkatkan brand awareness. Tingkat brand awareness konsumen 
diperlukan untuk membangkitkan pembelian yang bervariasi, tergantung pada cara pembuatan brand awareness dan dimana keputusan itu dibuat untuk kategori produk atau bentuk produkTerdapat indikator menurut Iskandar dan Sari (2017: 284) yang digunakan sesuai dengan penelitian ini untuk mengetahui seberapa jauh konsumen sadar terhadap sebuah brand antara lain,

1. Konsumen yang dapat mengingat ketika ditanya merek apa saja yang diingat.

2. Konsumen yang dapat mengenali merek tersebut termasuk dalam kategori tertentu.

\section{Keputusan Pembelian}

Menurut Manampiring dan Trang (2016: 474) menyatakan keputusan pembelian adalah proses penyelesaian masalah yang terdiri dari pengenalan kebutuhan dan keinginan, pencarian informasi, penilaian sumber seleksi pada alternatif pembelian, keputusan pembelian dan perilaku setelah pembelian. Menurut Nopriani (2016: 2) keputusan pembelian adalah keputusan konsumen mengenai pilihan atas merek-merek yang ada di dalam kategori pilihan. Terdapat indikator dari keputusan pembelian, yaitu:

1. Kemantapan pada sebuah produk.

2. Kebiasaan dalam membeli produk.

3. Memberikan rekomendasi kepada orang lain.

4. Melakukan pembelian ulang.

\section{METODOLOGI PENELITIAN}

Populasi dalam penelitian ini adalah konsumen yang sudah pernah membeli produk scarf ASTYLE. Jumlah sampel yang dijadikan dalam penelitian ini adalah sebanyak 52 responden. Pengambilan sampel pada penelitian ini dilakukan dengan teknik accidental sampling. Accidental sampling yaitu bentuk pengambilan sampel secara kebetulan dimana dan siapa saja yang bertemu dengan peneliti serta dianggap tepat menjadi sumber data dalam penelitian ini (Timpal et al., 2016: 312). Dengan menentukan kriteria sampel yaitu konsumen yang telah membeli produk scarf ASTYLE dan mengetahui advertising ASTYLE.

\section{ANALISA DAN PEMBAHASAN \\ Model Analisis Jalur}

Analisis jalur digunakan untuk menganalisis hubungan sebab akibat yang terjadi pada regresi berganda jika variabel bebas mempengaruhi variabel terikat tidak hanya secara langsung tetapi juga secara tidak langsung (Danang Sunyoto, 2012). Pada penelitian ini menggunakan software SPSS untuk menguji pengaruh advertising (X) terhadap keputusan pembelian (Y) dengan brand awareness (Z) sebagai variabel mediasi.

Tabel 1

Ringkasan Hasil Uji Substruktur

\begin{tabular}{|c|c|c|c|c|}
\hline Model & $\begin{array}{c}\text { Unstandardized } \\
\text { Coefficients }\end{array}$ & t hitung & Sig. & Keterangan \\
\hline $\mathrm{X} \rightarrow \mathrm{Z}$ & 0,793 & 6,871 & 0,000 & Signifikan \\
\hline $\mathrm{X} \rightarrow \mathrm{Y}$ & 0,324 & 2,666 & 0,010 & Signifikan \\
\hline $\mathrm{Z} \rightarrow \mathrm{Y}$ & 0,366 & 3,432 & 0,001 & Signifikan \\
\hline
\end{tabular}

Sumber: Data diolah Peneliti, 2018 


\section{Uji Mediasi}

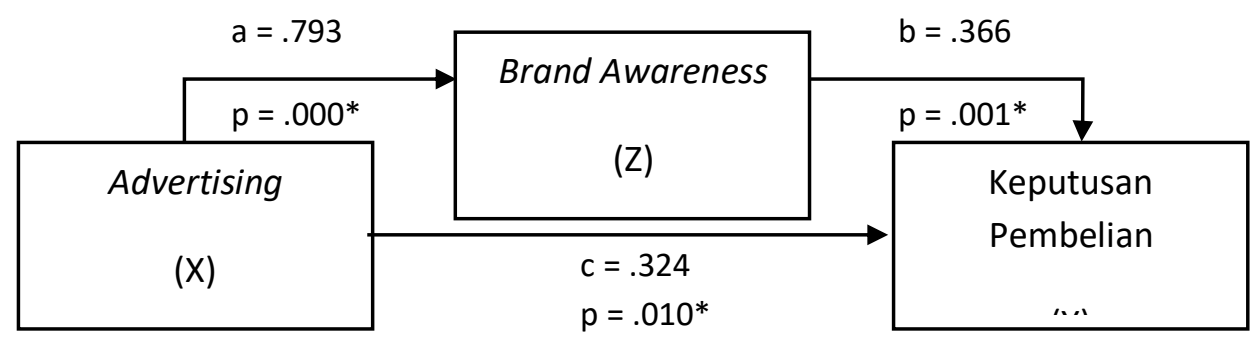

Gambar 1

Hasil Model Analisis Jalur

Tabel 2

Hasil Pengaruh Langsung Dan Pengaruh Tidak Langsung

\begin{tabular}{|l|c|c|}
\hline \multicolumn{1}{|c|}{ Tipe Pengaruh } & Variabel & $\begin{array}{c}\text { Standard Koefisien } \\
\text { Beta }\end{array}$ \\
\hline Pengaruh Langsung & $\mathrm{X} \rightarrow \mathrm{Y}$ & 0,324 \\
\hline $\begin{array}{l}\text { Pengaruh Tidak } \\
\text { Langsung }\end{array}$ & $\mathrm{X} \rightarrow \mathrm{Z} \rightarrow \mathrm{Y}$ & 3,06427363 \\
\hline $\begin{array}{l}\text { Hasil Hubungan Tidak } \\
\text { Langsung }\end{array}$ & $\mathrm{X} \rightarrow \mathrm{Z} \rightarrow \mathrm{Y}$ & $\mathrm{IE}>\mathrm{DE}$ \\
\hline
\end{tabular}

Berdasarkan Tabel 2 dapat disimpulkan bahwa pengaruh langsung variabel advertising dan keputusan pembelian memiliki standar koefisien beta sebesar 0,324, dan pengaruh tidak langsung antara variabel advertising $(\mathrm{X})$, brand awareness $(\mathrm{Z})$ dan keputusan pembelian $(\mathrm{Y})$ memiliki standar koefisien beta 3,06427363 dimana menunjukkan standar keofisien beta pengaruh tidak langsung lebih besar dari pada standar koefisien beta pengaruh langsung. Maka dapat disimpulkan pengaruh tidak langsung dengan menempatkan brand awareness sebagai variabel mediasi lebih berpengaruh. Brand awareness produk ASTYLE secara signifikan mampu memediasi pengaruh advertising terhadap keputusan pembelian.

\section{Pembahasan}

Berdasarkan tabel nilai signifikansi uji t maka disimpulkan bahwa variabel advertising secara individu memiliki pengaruh signifikan terhadap variabel brand awareness ( $\mathrm{Z}$ ), sehingga hipotesis pada penelitian ini yang menyatakan bahwa advertising berpengaruh signifikan terhadap brand awareness produk ASTYLE dapat diterima serta rumusan masalah pertama pada penelitian ini dapat terjawab. Berpengaruhnya advertising terhadap brand awareness produk dikarenakan selama ini memberikan informasi yang mudah dipahami oleh konsumen, seperti informasi yang diberikan melalui story Instagram, fitur periklanan Instagram, kolom deskripsi Instagram, kolom deskripsi di setiap gambar yang diupload di Instagram sehingga kejelasan informasi yang diberikan membuat brand ASTYLE diingat oleh konsumen. ASTYLE melakukan kegiatan penjualan salah satunya secara online melalui Instagram. Penjualan di Instagram sangat diminati oleh pelaku bisnis pemula karena dirasa sangat efektif untuk melakukan promosi secara online dan hanya mengandalkan gadget. Berdasarkan hasil penelitian sebagian responden ASTYLE berusia 20 - 25 tahun, dimana pada usia tersebut adalah anak muda yang sebagian besar pengguna media sosial Instagram sebagai media konsumsi mereka, dan sangat cocok dengan target pasar ASTYLE dengan usia 16 - 30 tahun. Adanya kejelasan informasi yang diberikan di Instagram dapat memberikan pemahaman bagi konsumen sehingga menarik konsumen untuk melakukan pembelian. Hasil penelitian ini mendukung penelitian yang dilakukan oleh Bangun dan Saputri (2016) menunjukkan adanya pengaruh advertising secara positif terhadap brand awareness. 
Variabel advertising $(\mathrm{X})$ memiliki pengaruh signifikan terhadap variabel keputusan pembelian (Y), sehingga hipotesis pada penelitian ini yang menyatakan bahwa advertising berpengaruh terhadap keputusan pembelian produk ASTYLE dapat diterima serta rumusan masalah kedua pada penelitian ini dapat terjawab. Berpengaruhnya advertising terhadap keputusan pembelian produk dapat disimpulkan bahwa dengan kejelasan informasi yang diberikan dapat mendukung kebiasaan konsumen yang cenderung teliti dengan produk yang akan dibeli yang dapat mempermudah konsumen dalam memahami isi informasi yang diberikan sehingga timbul keputusan pembelian. Konsumen yang teliti pada produk yang akan dibelinya akan lebih percaya pada produk ASTYLE dengan didukungnya informasi yang diberikan ASTYLE selama ini jelas sehingga dapat lebih meningkatkan keputusan pembelian produk ASTYLE. Hasil penelitian ini mendukung penelitian yang dilakukan oleh Siregar dan Widodo (2018: 1134) dengan hasil penelitian menunjukkan bahwa periklanan memiliki pengaruh yang signifikan terhadap keputusan pembelian.

Variabel brand awareness $(Z)$ memiliki pengaruh signifikan terhadap variabel keputusan pembelian (Y). Berpengaruhnya brand awareness terhadap keputusan pembelian produk ASTYLE dikarenakan selama ini ASTYLE telah melakukan promosi secara rutin. Tak hanya promosi melalui media sosial Instagram, namun ASTYLE sering mengikuti bazar dan pameran, ASTYLE aktif dalam melakukan presentasi pada saat bazar, pameran, acara kampus hingga pada saat lomba. ASTYLE juga menggunakan jasa endorse (celebrity endorser) sehingga akan mempermudah konsumen mengingat produk apa saja yang telah digunakan oleh selebritis tersebut. Upaya advertising yang dilakukan selama ini telah mampu memberikan pengetahuan mengenai produk serta menanamkan merek ASTYLE pada benak konsumen. Kebanyakan orang akan membeli produk yang mereka kenal sebab konsumen telah memberikan kepercayaannya terhadap kualitas dan manfaat yang diberikan produk tersebut. Berdasarkan identifikasi responden yang di dapat, sebagian besar konsumen produk adalah berjenis kelamin perempuan yang merupakan perempuan lebih mengikuti tren fesyen sehingga memiliki nilai standar jenis dan merek produk tersendiri dimana konsumen akan mengingat dan menanamkan merek produk tersebut. Sesuai dengan target pasar yang menetapkan perempuan remaja hingga dewasa. Konsumen yang telah membeli produk telah mengetahui produk yang dijual oleh ASTYLE adalah produk fesyen scarf, bukan karena merek ASTYLE cukup dikenal hingga luas. Hasil penelitian ini mendukung penelitian yang dilakukan oleh Setiawati dan Lumbantobing (2017: 78) dengan hasil penelitian menunjukkan bahwa hipotesis penelitian brand awareness signifikan berpengaruh positif terhadap keputusan pembelian.

\section{KESIMPULAN DAN SARAN}

Berdasarkan hasil penelitian dan pembahasan Pengaruh Advertising Terhadap Keputusan Pembelian Produk ASTYLE dengan Brand Awareness sebagai Variabel Mediasi, dapat disimpulkan advertising berpengaruh signifikan terhadap brand awareness produk ASTYLE, advertising berpengaruh signifikan terhadap keputusan pembelian produk ASTYLE, brand awareness berpengaruh signifikan terhadap keputusan pembelian produk. Dalam meningkatkan kesadaran merek akan produk ASTYLE, perlu melakukan peningkatan kualitas seperti desain dan ukuran scarf sehingga dapat menciptakan kesadaran merek sesuai ciri khas produk ASTYLE. Keberhasilan suatu usaha tidak hanya melakukan peningkatan dari advertising dan brand awareness saja, sehingga bagi peneliti selanjutnya disarankan untuk memperbesar jumlah sampel dan melakukan penelitian dengan mempertimbangkan variabel lain yang dapat mempengaruhi keputusan pembelian konsumen, seperti kualitas produk, harga dan kualitas layanan. 


\section{DAFTAR PUSTAKA}

Ariprayugo, G., dan Santoso, S, B. (2016). Analisis Pengaruh Advertising dan Public Relations Terhadap Keputusan Pembelian Produk Hijau (Studi pada Pengguna Produk Hijau The Body Shop Semarang), Diponegoro Journal of Management, Volume 5, Nomor 2, Tahun 2016.

Bangun, B, T., dan Saputri, M, E. (2016). Pengaruh Advertising Terhadap Pembentukan Brand Awareness pada Zalora Indonesia (The Effect of Advertising on Brand Awareness in Zalora Indonesia), Journal e-Proceeding of Management, Vol. 3, No. 2, Agustus 2016.

Dwivedi, A., Johnson, L.W., \& Mc Donald, R.E. (2015). Celebrity endorsement, self brand connection and consumer based brand equity. Journal of Product \& Brand Management, 24(5), 449-461.

Iskandar, D, A., dan Sari, S, D, S, R. (2017). The Effect Of Event And Publicity Towards Brand Awareness On Financial Service Authority (OJK), Jurnal Riset Manajemen dan Bisnis, Vol. 2, S1, September 2017.

Manampiring, A, F., dan Trang, I. (2016). Pengaruh Produk, Harga, Promosi dan Tempat Terhadap Keputusan Pembelian Mobil di PT. Astra Internasional TBK., Jurnal EMBA, Vol. 4, No.1, Maret 2016.

Oladepo, I. \& Abimola, S. (2015). The Influence Of Brand Image And Promotional Mix On Consumer Buying Decision - A Study Of Beverage Consumer On Lagos State. British Journal of Marketing Studies, 3(4), 97-109

Putra, D, R, P., dan Rachmi, A. (2017). Pengaruh Periklanan dan Brand Image Terhadap Keputusan Pembelian Pomade Timeless Deluxe di Gresik, Jurnal Aplikasi Bisnis, EISSN: 2407-5523, ISSN: 2407-3741, 2017.

Setiawati, M., dan Lumbantobing, R. (2017). Pengaruh Promosi dan Kemasan Terhadap Keputusan Pembelian Produk Chitato yang Dimediasi oleh Brand Awareness, Jurnal Manajemen Bisnis, Vol. 12, No. 1, 2017.

Siregar, A, G, S., dan Widodo, A. (2018). Pengaruh Periklanan Sosial Media Terhadap Keputusan Pembelian Konsumen (Study Pada Konsumen Nasi Goreng Mafia di Kota Bandung), Journal e-Proceeding of Management, Vol. 5, No.1, Maret 2018.

Timpal, N., Lapian, S, L, H, V, J,. dan Rate, P, V. (2016). Pengaruh Brand Awareness dan Brand Attiude Terhadap Keputusan Pembelian Handphone Merek Nokia (Studi Kasus pada Siswa SMA dan SMK di Kota Manado), Jurnal Berkala Ilmiah Efisiensi, Volume 16, No. 1, 2016. 